\title{
An Electronic Control System for Pesticide Application Proportional to the Canopy Width of Tree Crops
}

\author{
F. Solanelles ${ }^{1}$; A. Escolà ${ }^{1,2}$; S. Planas ${ }^{3}$; J. R. Rosell²; F. Camp²; F. Gràcia ${ }^{1}$
}

5

\footnotetext{
${ }^{1)}$ Centre de Mecanització Agrària (CMA), Generalitat de Catalunya, Rovira Roure 191, 25198, Lleida, Spain; e-mail of corresponding author: fsolanelles@gencat.net

${ }^{2)}$ Universitat de Lleida. Departament d'Enginyeria Agroforestal, Rovira Roure 191, 25198, Lleida, Spain; e-mail: aescola@eagrof.udl.es 08007, Barcelona, Spain; e-mail: santiplanas@gencat.net
} 


\section{Abstract}

A prototype of an electronic control system based on ultrasonic sensors and proportional solenoid valves for a proportional application to the canopy width of tree crops was mounted on an air-assisted sprayer. The sprayer flow rate adjustment was based on the relationship between the actual tree width measured by the ultrasonic sensors and the maximum tree width of the orchard. The prototype was tested in olive, pear and apple orchards to assess the system performance in different crop geometries. The spray deposit distribution was measured in comparison with conventional air-assisted applications. Metal tracers were used so that spray deposits for each treatment could be measured on the same samples, reducing sampling variability. Liquid savings of $70 \%, 28 \%$ and $39 \%$ in comparison to a conventional application were recorded in the olive, pear and apple orchard respectively, which resulted in lower spray deposits on the canopy but a higher ratio between the total spray deposit and the liquid sprayer output (i.e. better application efficiency). A reduction of the maximum tree width parameter in the control algorithm in the apple orchard reduced spray savings but increased spray deposition, with spray savings mainly in the middle level of the outside canopy, compared to conventional air-assisted applications.

\section{Introduction}

The different shapes and sizes found in tree crops, even during the same growing season, makes necessary a continual adjustment of the applied dose to optimise the spray application efficiency. A real time control systems on sprayers is necessary to achieve a constant spray deposit on the crop canopies and to reduce spray losses. These systems are based on different kinds of physical properties, which may allow the monitoring of canopies. For instance, it is 
possible to use, reflected light spectrum analysis, laser-based probes or ultrasonic sensors. An example of the use of a spectrum analysis system to switch off the spray in the gaps found in the top of and between fruit trees is presented by Jaeken et al. (1997). Since the sprayer prototype presented in this communication is based on canopy detection by means of 5 ultrasonic sensors, it is important to refer to some of the background of this technology.

In the USA, the performance of a sprayer prototype using ultrasonic sensors was tested by Giles et al. (1987). The system adjusted the flow rate of the sprayer to the canopy size variations measured by the sensors. The spray boom was divided into three sections each side and these sections were independently turned on and off according to the readings of ultrasonic sensors, placed at different heights. Spray savings were reported but there was also less spray deposition on some foliage areas when the control system was used.

In the late eighties, sprayer models appeared on the market, which were able to turn off the spray when there was a gap between trees (Perry, 1995). This is very useful for saving spray in young orchards or when there are wide gaps between trees, reducing the spray drift and the chemical cost. However these systems do not account for variations in canopy shape, which are found in most of the orchards.

More recently, another approach was made by Balsari and Tamagnone (1998) with an ultrasonic control system mounted on a ducted air-assisted sprayer. In this case the number of working nozzles could be adjusted to tree height, according to the readings of sensors placed at different heights. Moltó et al. (2001) developed a prototype to turn off the spray in the gap between two tree canopies and with the possibility of making up for the variation of canopy 
volume at the beginning and end of each tree, by means of the action of two electrovalves at each boom section.

Ultrasonic sensors have also been used for real-time mapping of citrus groves to help users to manage them site-specifically using variable rate technology for a more efficient use of inputs (Schumman \& Zaman, 2005). Canopy density increases the difference between ultrasonic and manually measured volume, whereas there is no effect of the working speed on the measurement results (Zaman \& Salyani, 2004). Tree crop mapping has also been made using light detection and ranging systems (LIDAR) with the aim of testing different spray volume deposition models in apple orchards (Walklate et al. 2002) and improving the pesticide dose expression (Walklate et al. 2003).

Proportional application systems can modify the volume application rate from zero to full application in a continuous way. Rosell et al., 1996 reported on a prototype with proportional response operating on a 3-nozzle boom section commanded by an electrovalve with a known relationship between signal and flow rate and fast enough to account for small variations in canopy size. A further improvement of the system was tested in the field and the first results were presented in Solanelles et al., 2001 and Escolà et al., 2003. The final aim of this work was to build and improve a prototype of electronic control system based on ultrasonic sensors for an application proportional to the canopy width and assess its performance in several tree crops.

\section{Materials and methods}




\subsection{Electronic control system}

The steps followed to design the new control system were, first, to seek better, up-to-date sensors suitable for spray control, then to screen the market for a reliable proportional electrovalve which could offer improved performance over the one that was used by Rosell et al., 1996 and, finally, to design a control unit with the possibility of making a lot of changes in the control programme. Rosell et al. 1996 used a datalogger for data collection and operation control, so it was time-consuming to make any change in the software. It was also important to install a measuring system on the prototype to monitor and record liquid flow rate and working pressure at a suitable measuring rate during the tests.

As a result of this work, the prototype was assembled with ultrasonic sensors (Siemens, Munich, Germany) with a working range of $0.4 \mathrm{~m}$ to $3.0 \mathrm{~m}$ and proportional solenoid valves (Asco Joucomatic, Rueil, France) with a maximum differential pressure of 8 bar, and a maximum flow rate $5 l \mathrm{~min}^{-1}$ (tested on a workbench in specific working conditions). The control system was based on the LabVIEW 4.0 software (National Instruments Corporation, Austin, USA) running on a laptop computer. The computer was interfaced with the prototype through NUDAM 6000 remote modules (Industrial PC Inc, Indiana, USA) for data acquisition and operation. There was also a measuring system (IROT S.A., Bizkaia, Spain) connected to another laptop computer for monitoring and recording measurements of a pressure probe (PCB Piezotronics Inc, New York, USA) and an electromagnetic flow meter (Endress+Hauser, Reinach, Switzerland) with a measuring range of 0-30 $l \mathrm{~min}^{-1}$. The system was powered at $12 \mathrm{~V}$ dc from the tractor battery. The supply was transformed to $24 \mathrm{~V}$ dc and $220 \mathrm{~V}$ ac wherever necessary. 
The different components and the control system were tested and fine-tuned in the laboratory and, when the sprayer prototype was fully assembled, it was tested in the field. This process yielded a control system for a continuous variation of liquid flow rate according to the canopy width (vegetation volume). The control algorithm of the system was based on establishing a maximum liquid flow rate from the volume application rate chosen for the crop. This maximum flow rate was to be delivered wherever the crop canopy had a maximum width and a continuous variation was defined from zero (no crop) to this maximum.

The real time flow rate of each electrovalve of the sprayer prototype was computed by:

$$
q=p \frac{a v V_{R}}{600 N}
$$

where: $a$ is the tree row spacing in $\mathrm{m} ; v$ is the speed in $\mathrm{km} \mathrm{h}^{-1} ; V_{R}$ is the volume application rate for the orchard in $l$ ha $^{-1} ; N$ is the number of nozzle sections; and $p$ is the reduction coefficient of the maximum flow rate given by:

$$
p=\frac{c}{C}
$$

where: $c$ is the actual tree width in $\mathrm{m}$; and $C$ is the maximum tree width of the orchard in $\mathrm{m}$. The tree width $c$ was computed from the distance between the sensor and the outside of the canopy $d$ in m, by means of:

$$
\frac{c}{2}=\frac{a}{2}-e-d
$$

where: $a$ is the tree row spacing in $\mathrm{m}$; and $e$ is the distance from the sensor to the sprayer axis in $\mathrm{m}$ (Fig. 1). All the parameters, except for $c$, had to be provided to the control system by the operator, before starting the application. An empirical relationship between $q$ and the signal to 
be sent to the electrovalve was stored in the control system memory and used to command each electrovalve on a real time basis. This relationship was obtained in the laboratory using the same electrovalve and nozzles that were used in the prototype.

\subsection{Sprayer prototype}

The control system was fitted to a mounted air-assisted sprayer equipped with a piston pump, a $200 l$ tank, a pressure-limiting valve, a blower unit with an axial fan and a nozzle boom around the air outlet. The prototype was fully operative on one side. There were two 3nozzle boom sections with one electrovalve mounted in each one. Two ultrasonic sensors were placed $80 \mathrm{~cm}$ in front of the nozzle plane in the direction of travel, at 120 and $200 \mathrm{~cm}$ above the ground. Each sensor commanded one electrovalve but it was also possible to command both electrovalves with only the sensor placed at $120 \mathrm{~cm}$. At the same time a bypass valve in the sprayer manifold allowed the prototype to work as a conventional sprayer to be used as reference in the field tests. To avoid spraying at too low pressures, an anti drip device was mounted on each nozzle with an internal spring set to open at 1.5 bar (Fig. 2). These devices also helped to shorten response times by keeping the pipes full, ready to spray when the pressure exceeded the one set with the springs. The spraying conditions used in the field tests are given in Table 1. Yellow and orange Albuz nozzles (Saint-Gobain Ceramiques Avancees Desmarquest, Evreux, France) were used. The Volume Median Diameter of the spray with the Albuz orange nozzles was $148 \mu \mathrm{m}$ in the conventional applications and $156 \mu \mathrm{m}$ in the proportional application, according the measurements carried out with a phase Doppler particle analysing system (Dantec Dynamics A/S, Skovlunde, Denmark). 


\subsection{Field tests}

\subsubsection{First series of tests}

The first series of tests were planned in order to check the general performance of the assembled prototype. Two kinds of tree crops were used: an olive orchard cv. Arbequina and a pear orchard cv. Conference. In the first case, the row spacing was $5 \mathrm{~m}$ and the tree spacing was $4 \mathrm{~m}$. Therefore, there were gaps in between olive tree canopies and the trees were mainly globular. On the other hand, the pear canopies were closer together, with a distance of $1.5 \mathrm{~m}$ between trees and $4 \mathrm{~m}$ between rows. Gaps were restricted to the top of the crop and the general shape of the crop was more like a wall.

Field tests comprised spray applications in each kind of crop comparing the control system performance with a conventional spray application, made with the same sprayer prototype without the control system. In the olives trees two possible control situations were tested (one commanding sensor or two commanding sensors). For the pear trees only the two commanding sensor option was tested. Two passes were made up and down one tree row so it was treated on both sides. During the application, the pressure and the liquid flow rate were recorded by the measuring system on the prototype and spray savings were computed in comparison to a conventional application.

Figure 3 shows the sampling strategy in the olive orchard, similar to that used in the pear orchard, although in the latter case canopy orientations along and across the row were not considered. It can be seen that different canopy levels and the inside and outside of the canopy are taken into account for defining canopy sampling zones. The tests were made in a three replication basis. 
In both crops, canopy deposits were measured on composite leaf samples, taken from the different canopy zones of one selected tree in each replication. In pear trees, each sample had five leaves, whereas in olive trees there were 15 leaves in each sample, because of their smaller size. Spray losses to the ground were measured with filter paper strips $(50 \times 3 \mathrm{~cm})$ placed on the ground below the treated row and spray drift by means of $2 \mathrm{~mm}$ plastic strings up to $10 \mathrm{~m}$ high on the next alley downwind the last sprayer track. Collector samples were picked up in plastic bags and taken to the laboratory. The range of the mean values of the meteorological conditions recorded during the tests is shown in Table 2

Metal chelates of Fe, Zn and Mn (Sarcan Fe, Zn and Mn by Exclusivas Sarabia S.A., Lleida, Spain), which are registered for use in fruit orchards, were used as tracers. The concentration of metal in the applied liquid was between 2 and $3 \mathrm{~g} l^{-1}$. Each sample was washed off with distilled water in the same plastic bag and the concentration of each metal was determined by atomic absorption spectroscopy, following Travis et al. (1985) and Murray et al. (2000). Nevertheless, previous tests were made in the laboratory to confirm the accuracy of the methodology, especially in relation to tracer recovery from each kind of sample. The use of filter paper collectors with metal chelates tracers was reported by Nuyttens et al. 2004. In the case of leaf samples, the total leaf area was measured using an image analysing system (Delta T Devices Ltd, Cambridge, UK).

\subsubsection{Second series of tests}

Once the results of these first tests were known, a second series of tests in an apple orchard cv. Golden (tree spacing $1.5 \mathrm{~m}$, row spacing $4 \mathrm{~m}$ ) was planned for the next season, with the same spray distribution measurement methodology. The corresponding application conditions 
and meteorological measurements are also presented in Tables 1 and 2. The objective of these tests was to modify and improve the algorithm that relates the required spray output of the sprayer to the crop canopy characteristics, by means of reducing the maximum tree width in Eqn (2), which is used as an input parameter by the control software, in relation to the actual tree width of the crop. To this effect, the tree width of a crop row section was measured with the ultrasonic sensors and recorded by the data acquisition system of the prototype at $10 \mathrm{~Hz}$ and a forward velocity of $0.8 \mathrm{~m} \mathrm{~s}^{-1}$. From these data, three threshold values were obtained, so that $50 \%, 70 \%$ and $90 \%$ of the number of measured values were below each threshold and denoted by $C_{50}, C_{70}$ and $C_{90}$. The values for the reduction coefficient in Eqn 1 were specified as 1 when $c \geq C_{n}$ and as $c / C_{n}$ when $c<C_{n}$.

The control system hardware was also improved, by means of replacing the NUDAM units and the laptop computer by a compact, more robust control device, based on a microprocessor and fitted with a keyboard and a display.

\section{Results and discussion}

\subsection{First series of tests}

The spray deposit values on the leaf and artificial collector samples are presented as both the amount of measured liquid spray (Figs $4 \& 5$ ) and the normalised tracer deposit (Tables 3, 4, and 5) given by:

$$
d_{n}=\frac{C V D_{N}}{A D}
$$


where: $\mathrm{C}$ is the concentration of metal tracer in the water extract in $\mathrm{mg} l^{-1} ; V$ is the water volume used in the extraction in $\mathrm{ml} ; D_{N}$ is the normalising metal tracer dose rate in $\mathrm{g} \mathrm{ha}^{-1}$; $A$ is the collector area in $\mathrm{cm}^{2}$; and $D$ is the actual metal tracer dose rate in each application in $\mathrm{g}$ ha 1. The objective of normalising the spray deposit values is to compare the efficiency of the 5 conventional and the proportional applications in each crop.

Spray savings measured in the proportional application in the olive orchard were $68 \%$ with one control sensor and $72 \%$ with two control sensors in comparison with a conventional treatment. Therefore, there was a higher reduction of the spray application volume when the sprayer boom was divided in 3-nozzle sections (two control sensors for each sprayer side), since it was possible to account for a lower canopy width at the treetop (Fig. 6). The low volume application rate delivered in the proportional application could explain a reduction of spray deposit uniformity as it is stated below. This could be improved adjusting the geometrical input parameters of the control unit (i.e. maximum tree width) as it was done in the second series of tests.

In the pear orchard, spray savings accounted for $28 \%$ of the spray output of the conventional application, most of it in the top half of the canopy. Spray savings were much lower, but they are still high enough to be considered as an advantage, as long as the quantity and uniformity of the spray deposit on the canopy does not decrease.

Measured spray (liquid) deposits on the canopy were higher in the conventional application both in olives and pears (Fig. 4). Average measured values were $2.87 \mu l \mathrm{~cm}^{-2}$ for the conventional application in the olive orchard and $1.02 \mu l \mathrm{~cm}^{-2}$ for the proportional application, with two control sensors. In the pear orchard the corresponding values were $0.86 \mu l \mathrm{~cm}^{-2}$ and 
$0.55 \mu l \mathrm{~cm}^{-2}$. It could be expected to get the same amount of spray deposited in both kinds of treatments, since when the control system is deployed, no spray is emitted when there is no vegetation. The reason for a lower spray deposit may be that droplets do not follow a straight trajectory from the nozzle to the canopy, but they swirl around pushed by the vortices of the 5 turbulent air jet. Therefore they do not fall on the target they were aimed at.

However, in the olive orchard, the volume application rate in the conventional application was much higher than in the proportional application, as it was the tracer application rate. When deposit values are normalised to the same tracer application rate (Table 3) it is evident that the spray deposit on the canopy was higher with a proportional application. Therefore, the ratio between the spray deposit on the canopy and the sprayer output was also higher. This was caused by lower spray drift losses because the spray is turned off between the trees, but losses to the ground do not follow a clear trend since the measured value in the conventional treatment is in the middle of both proportional treatment values.

It is important to point out that whenever the sensor control was activated there was an increase of spray deposit variability on the canopy. Again, because of the distance from the nozzle outlet to the tree canopy and the turbulence in the air flow, the spray concentration in the air flow reaching the canopy may not match the canopy width at a given place. There are no patterns which may explain the higher spray deposit variation (i.e. worse spray penetration inside the canopy or lower spray deposit at the tree top), as it can be seen in Fig. 4 but it is caused by unexpected high or low deposit values at any place on the canopy.

Spray deposit values on the pear orchard follow a similar pattern of that found in the olive orchard: more liquid deposit on leaves when a conventional application was used but high 
tracer deposit values once deposit measurements were normalised to the same application rate (Table 4). However, the variation of the spray deposit on the canopy was similar in both treatments probably because of a more continuous spray flow than in the treatment in the olive orchard. There is also a visible trend towards a reduction of spray deposits on the right of the tree row when the control system is used (Fig. 4). When this side was treated, liquid flow records were also lower. It is thought that the sprayer run was not made exactly on the centre of the alley, but further away form the treated tree row. Therefore the distance measured to the outside of the treated row ( $d$ in Fig. 1) was greater than it should have been.

Spray drift was slightly higher with the conventional application, although the detection limit of metal cations measured by means of atomic absorption $\left(0.2 \mathrm{mg} \mathrm{l}^{-1}\right)$ is too high to measure low spray drift fluxes and real differences between treatments could were difficult to find. On the other hand, losses to the ground were clearly increased when the proportional application was used. There is the possibility that the slightly higher average droplet size produced by low working pressure used to deliver low liquid flows causes higher spray losses to the ground.

\subsection{Second series of tests}

The objective of these tests was to improve the spray deposit pattern on the canopy obtained with the proportional control system. To this effect the maximum tree width $C$, which is used as a geometrical input parameter as shown in Eqn (2), was decreased so that the spray output of the prototype was higher for the same amount of vegetation. Three maximum tree width values were tested: $C_{50}, C_{70}$ and $C_{90}$. The savings of spray liquid obtained by each 
setting up were $38.8 \%, 44.4 \%$ and $50.7 \%$, so that the higher the reduction in the value of $C$, the lower the savings.

Table 5 shows the normalised tracer deposit obtained with the conventional application and the three reductions in the value of $C$ tested in the apple orchard. As happened with the spray applications of the first series, the liquid deposits on the leaves were always higher with the conventional application (Fig. 4), but when the spray savings obtained with the proportional applications are taken into account (Table 5), the normalised tracer deposits are higher with the proportional applications. Therefore, the proportional applications still show a better efficiency. According to the test results, the best efficiency is achieved when a $C_{50}$ reduction is used, and this corresponds with the lowest liquid savings. Losses to the soil remain always higher with the proportional applications and spray drift losses are so low in all the applications that they are difficult to assess.

The distribution of the spray deposit on the different tree levels shows that spray liquid deposits are very similar for the conventional and $C_{50}$ proportional applications, although the volume application rate used in the proportional application was lower than that of the conventional application. The maximum difference between liquid deposits of the proportional and conventional applications was measured on the middle level of the apple trees and mainly on the outside of the canopy (Fig. 5). This canopy zone is where the higher spray deposits are usually found after an application with a conventional air-assisted sprayer. Therefore the proportional application can reduce the excessive spray deposit in those canopy areas, which are usually oversprayed. This aspect can be corroborated by a better spray deposit uniformity of the proportional application (Table 5) which implies a more uniform spray distribution all over the canopy that allows a best pesticide dosing. Moreover, the spray 
deposit on that specific zone for the proportional application is still higher than the average deposit value for the conventional application on the whole canopy.

\section{Conclusions}

The assessment of a first electronic control system for a proportional spray application to the canopy width in olive and pear orchards showed important product savings (28\%-72\%) in relation to a conventional application, together with a better application efficiency and lower spray drift losses. However, the average spray deposit on the tree canopy was lower. Other problems of this first prototype were a trend to increase spray deposit variability, especially in olive orchards, and more losses to the ground, together with more sensitivity to application conditions, like driving inaccuracies.

According to the test results in apple orchards of an second improved control system, it was possible to increase the spray deposit on the canopy decreasing the maximum tree width used as an input parameter in the control software, although the lower the tree width value, the lower the spray savings in relation with the conventional application. It was also seen that the lower spray deposits were measured in those canopy zones that are usually oversprayed with a conventional application, namely the middle level of the outside canopy.

A further improvement of this system can be achieved by spraying according to the measured canopy volume or by the use of laser-based sensors (LIDAR), which are able to measure other tree canopy parameters like leaf area density. 


\section{Acknowledgements}

This research was supported by the Spanish National Research and Development

Programme, AGF1998-0348-C03-02 Research Project. The authors wish to thank Estació Experimental de Lleida (IRTA) for permitting the use of their crops for the field tests. Finally, appreciation is expressed to Pere Fontbuté, Jaume Segués, Ángel Bustos, Elena Martínez, Montse Llorens and Patricia Bustos for their contribution to the experimental work.

\section{References}

Balsari P; Tamagnone M (1998). An ultrasonic airblast sprayer. EurAgEng Paper No. 98A-017, AgEng 98 International Conference, Oslo, Norway

Escolà A; Camp F; Solanelles F; Planas S; Rosell J R (2003). Tree crop proportional spraying according to the vegetation volume. First results. Proceedings of the VII Workshop on Spray Application Techniques in Fruit Growing. Cuneo, Italy

Giles D K; Delwicke M J; Dodd R B (1987). Control of orchard spraying based on electronic sensing of target characteristics. Transactions of the ASAE, 30(6), 1624-1630

Jaeken P; Doruchowski G; Holownicki R (1997). Use of sensors in selective spray application in orchards. Proceedings of the V Symposium on Fruit, Nut and Vegetable Production Engineering. Davis, USA 
Nuyttens D; Windey S; Sonck B (2004). Optimisation of a vertical spray boom for greenhouse spray applications. Biosystems Engineering, 89(4), 417-423, doi: 10.1016/j.biosystemseng.2004.08.016

Moltó M; Martín B; Gutiérrez A (2001). Pesticide loss reduction by automatic adaptation of spraying on globular trees. Journal of Agricultural Engineering Research, 78(1), 35-41, doi:10.1006/jaer.2000.0622

Murray R A; Cross J V; Ridout M S (2000). The measurement of multiple spray deposits by sequential application of metal chelate tracers. Annals of Applied Biology, 137, 245252

Perry R (1995). Sensor Controlled Orchard Sprayers; Proceedings of the National Conference on Pesticide Application Technology. Guelph, Canada, pp 164-171

Rosell J R; Nogués A; Planas S (1996). An experimental selective orchard spraying system based on the electronic control of applied flow rate. EurAgEng Paper No. 96A-120, AgEng 96 International Conference, Madrid, Spain

Schumman A W; Zaman Q U (2005). Software development for real-time ultrasonic mapping of tree canopy size. Computers and Electronics in Agriculture, 47(1), 25-40

Solanelles F; Planas S; Escolà A; Rosell J R (2001). Spray application efficiency of an electronic system for proportional application to the canopy volume. Aspects of Applied Biology, 66, 139-146 
Travis J W; Sutton T B; Skroch W A (1985). A technique for determining the deposition of heavy metals in pesticides. Phytopathology, 75, 783-785

Walklate P J; Cross J V; Richardson G M; Murray R A; Daker D E (2002). Comparison of different spray volume deposition models using LIDAR measurements of apple orchards. Biosystems Engineering, 82(3), 253-267, doi:10.1006/bioe.2002.0082

Walklate P J; Cross J V; Richardson G M; Daker D E; Murray R A (2003). A generic method of pesticide dose expression: Application to broadcast spraying of apple trees. Annals of Applied Biology, 143, 11-23

Zaman Q U; Salyani M (2004). Effects of foliage density and citrus speed on ultrasonic measurements of citrus tree volume. Applied Engineering in Agriculture, 20(2), 173-178 


\section{Table 1}

Spraying conditions during spray applications; volume application rate of the conventional application in each crop; Albuz turbulence nozzles (ATR model) were used; nozzle size is given by de corresponding model colour

5

\begin{tabular}{ccccc}
\hline Crop & $\begin{array}{c}\text { Volume application rate, } \\
l \text { ha }{ }^{-1}\end{array}$ & Nozzles & Pressure, bar & Working speed, $\mathrm{m} \mathrm{s}^{-1}$ \\
\hline & & & & \\
Olive & 520 & Yellow & 10 & 0.8 \\
Pear & 570 & Yellow & 10 & 0.8 \\
Apple & 500 & Orange & 8 & 1.1 \\
\hline
\end{tabular}


Table 2

Range of meteorological measurements during the spray applications

\begin{tabular}{ccccc}
\hline Crop & Temperature, ${ }^{\circ} \mathrm{C}$ & $\begin{array}{c}\text { Relative } \\
\text { humidity, } \%\end{array}$ & Wind speed, $\mathrm{ms}^{-1}$ & $\begin{array}{c}\text { Wind } \\
\text { direction }\end{array}$, deg \\
\hline Olive & $13.6-14.7$ & $49.8-52.4$ & $1.8-2.7$ & $30-44$ \\
Pear & $20.5-22.7$ & $49.0-54.4$ & $1.9-2.3$ & $16-41$ \\
Apple & $18.9-24.0$ & $60.5-75.4$ & $1.7-2.1$ & $30-78$ \\
\hline
\end{tabular}




\section{Table 3}

Spray deposition distribution measured on the olive orchard; values are given as the amount of the metal tracer per unit leaf area, normalised to an application rate of $\mathbf{4 3 0}$ g[metal] $\mathbf{h a}^{-1}$; values (means) in columns followed by the same letter do not differ significantly (Duncan's Multiple Range Test, $P=0.05$ ); $C V$, coefficient of variation; $P$, proportional application with (1) one sensor and (2) two sensors

\begin{tabular}{ccccc}
\hline Treatment & \multicolumn{2}{c}{ Canopy spray deposit } & $\begin{array}{c}\text { Losses to the soil, } \\
\mu g \text { [metal] } \mathrm{cm}^{-2}\end{array}$ & $\begin{array}{c}\text { Spray drift, } \\
\mu g \text { [metal] } \mathrm{cm}^{-2}\end{array}$ \\
\cline { 2 - 3 } & $\begin{array}{c}\text { Mean, } \\
\mu g\left[\text { metal] } \mathrm{cm}^{-2}\right.\end{array}$ & $C V, \%$ & & \\
\hline \\
Conventional & $2.37^{\mathrm{a}}$ & 28 & $0.48^{\mathrm{ab}}$ & 0.13 \\
P1 & $2.59^{\mathrm{b}}$ & 46 & $0.41^{\mathrm{a}}$ & 0.00 \\
P2 & $2.99 \mathrm{c}$ & 46 & $0.55^{\mathrm{b}}$ & 0.00 \\
\hline
\end{tabular}




\section{Table 4}

Spray deposition distribution measured on the pear orchard; values are given as the amount of the metal tracer per unit leaf area, normalised to an application rate of $\mathbf{1 0 0 0}$ g[metal] ha $^{-1}$; values (means) in columns followed by the same letter do not differ significantly (Duncan's Multiple Range Test, $P=0.05$ ); $C V$, coefficient of variation; $P 2$, proportional application with two sensors

\begin{tabular}{ccccc}
\hline Treatment & \multicolumn{2}{c}{ Canopy spray deposit } & $\begin{array}{c}\text { Losses to the soil, } \\
\mu g\left[\text { metal] } \mathrm{cm}^{-2}\right.\end{array}$ & $\begin{array}{c}\text { Spraydrift, } \\
\mu g\left[\text { metal } \mathrm{cm}^{-2}\right.\end{array}$ \\
\cline { 2 - 3 } & $\begin{array}{c}\text { Mean, } \\
\mu \text { [metal] } \mathrm{cm}^{-2}\end{array}$ & $C V, \%$ & & \\
\hline & $1.26^{\mathrm{a}}$ & 50 & $0.23^{\mathrm{a}}$ & 0.36 \\
Conventional & $2.14^{\mathrm{b}}$ & 47 & $0.87^{\mathrm{b}}$ & 0.31 \\
\hline
\end{tabular}




\section{Table 5}

Spray deposition distribution measured on the apple orchard, for three different reductions of the maximum tree width; values are given as the amount of the metal tracer per unit leaf area, normalised to an application rate of $945 \mathrm{~g}$ [metal] ha ${ }^{-1}$; values (means) in columns followed by the same letter do not differ significantly (Duncan's Multiple Range Test, $\mathrm{P}=0.05$ ); $\mathrm{CV}$, coefficient of variation; $C$, proportional application with different maximum tree width values

\begin{tabular}{|c|c|c|c|c|}
\hline \multirow[t]{2}{*}{ Treatment } & \multicolumn{2}{|c|}{ Canopy spray deposit } & \multirow{2}{*}{$\begin{array}{l}\text { Losses to the soil, } \\
\mu g\left[\text { metal] } \mathrm{cm}^{-2}\right.\end{array}$} & \multirow{2}{*}{$\begin{array}{c}\text { Spray drift, } \\
n g\left[\text { metal] } \mathrm{cm}^{-2}\right.\end{array}$} \\
\hline & $\begin{array}{c}\text { Mean, } \\
\mu g\left[\text { metal] } \mathrm{cm}^{-2}\right.\end{array}$ & $C V, \%$ & & \\
\hline Conventional & $1.78^{\mathrm{a}}$ & 53.0 & 0.47 & 2.50 \\
\hline$C_{50}$ & $2.68^{\mathrm{b}}$ & 45.5 & 0.75 & 0.82 \\
\hline$C_{70}$ & $2.05^{\mathrm{c}}$ & 45.9 & 0.61 & 5.39 \\
\hline$C_{90}$ & $2.19^{\mathrm{C}}$ & 45.5 & 0.87 & 4.05 \\
\hline
\end{tabular}




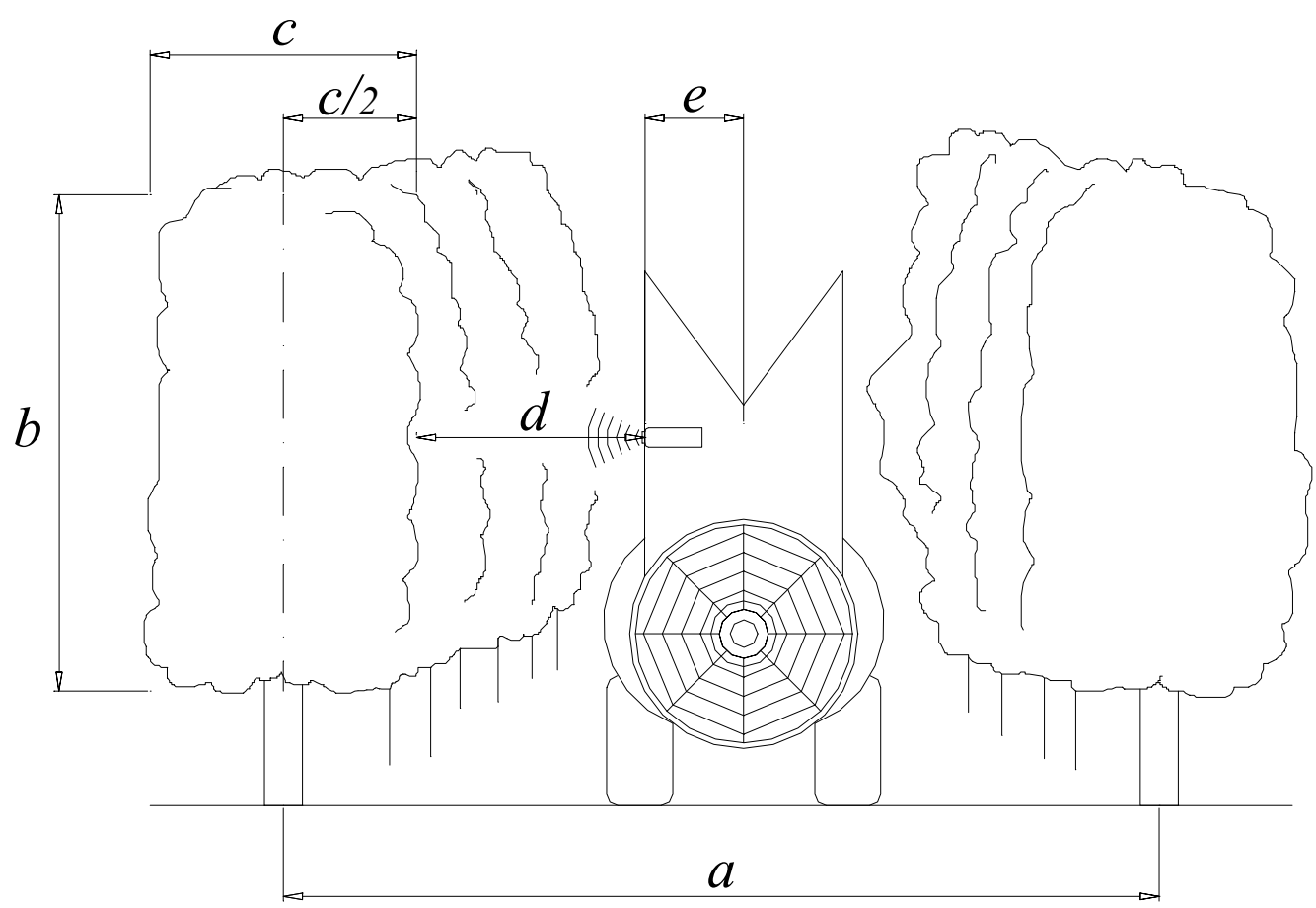

Fig. 1. Calculation of the tree canopy width (c) from the distance to the outside of the canopy (d), measured by the ultrasonic sensors; $e$, distance from the sensor to the sprayer axis; $b$, canopy height; a, tree row spacing 


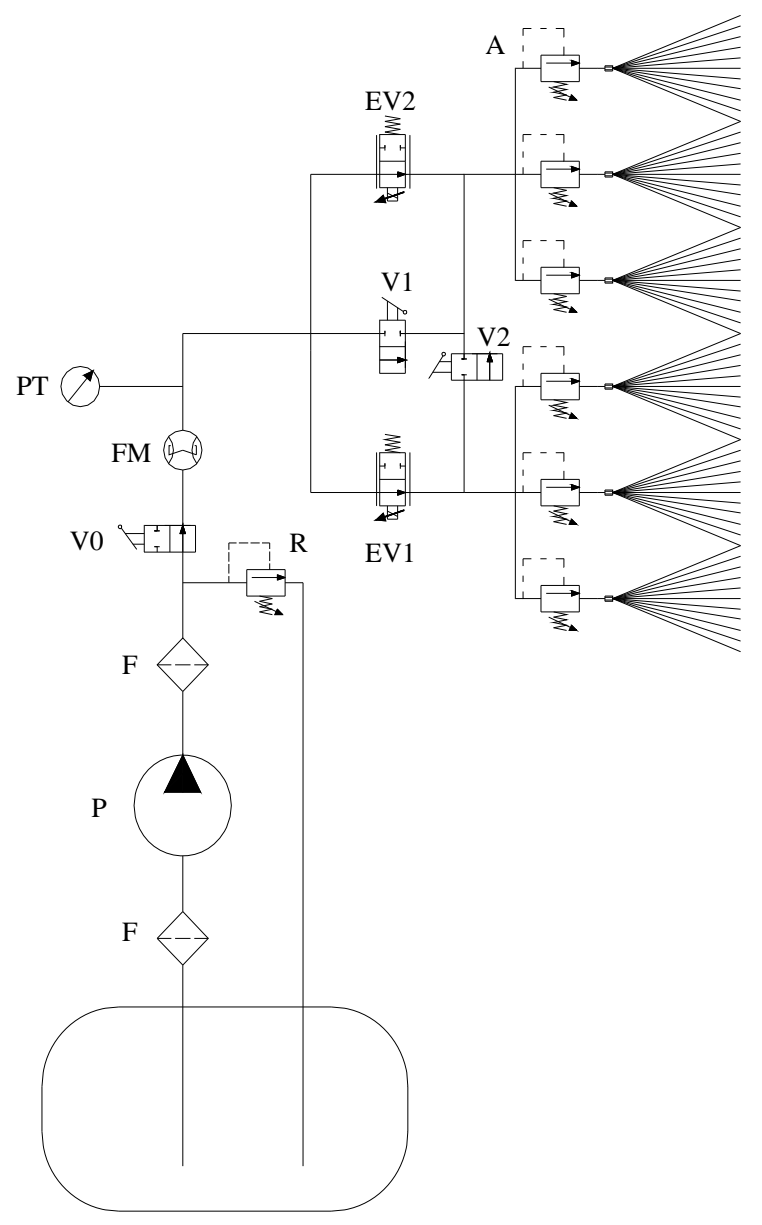

Fig. 2. Hydraulic circuit of the sprayer prototype; $F$, filter; $P$, pump; $R$, pressure regulator; $V$, valve; FM, flow meter; PT, pressure transducer; EV, proportional electrovalve; $A$, anti drip device 


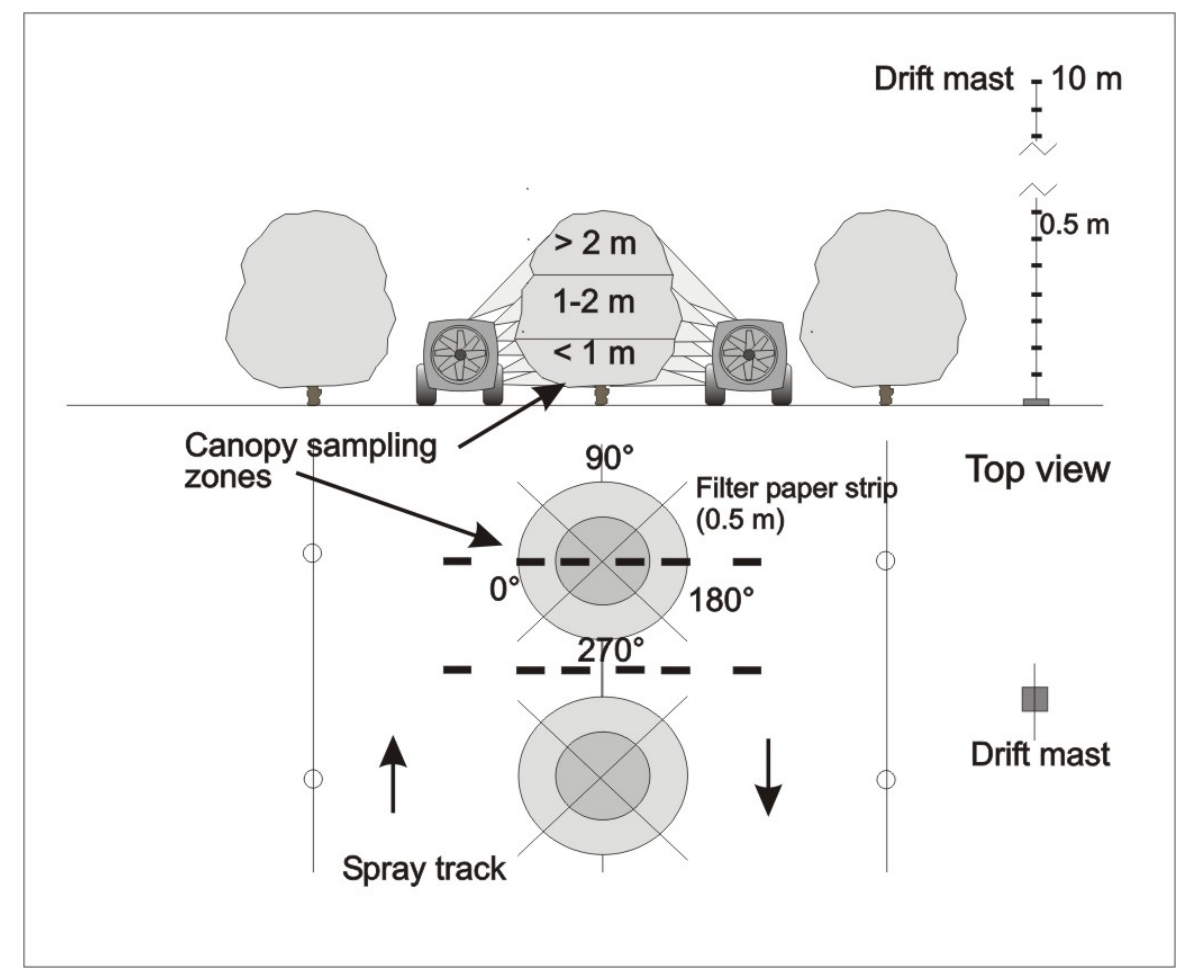

Fig. 3. Sampling strategy for one replication in the olive orchard trials 


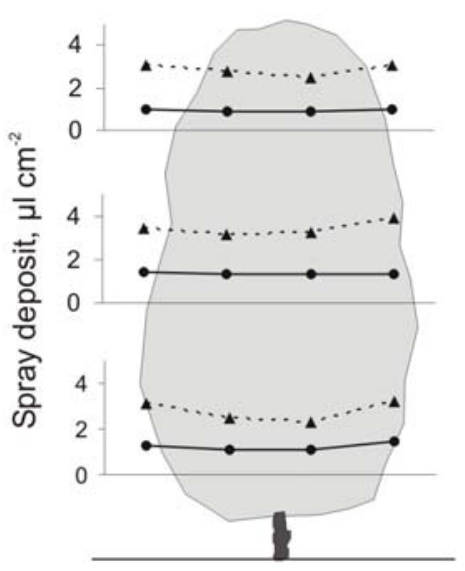

(a)

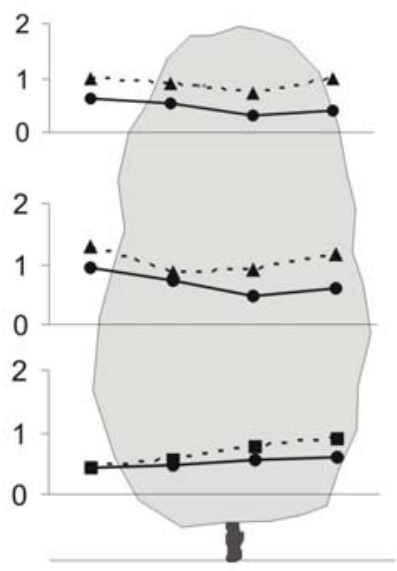

(b)

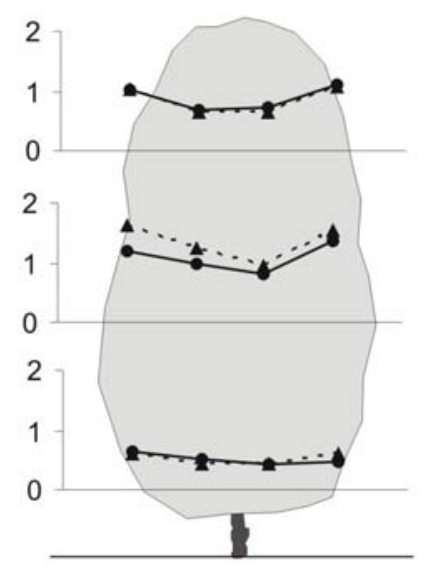

(c)

Fig. 4. Spray deposition on the (a) olive, (b) pear and (c) apple tree canopies measured after 5 the proportional ( - $\longrightarrow$ ) and conventional (.....) application; spray deposit values are shown as the amount of liquid per unit leaf area 


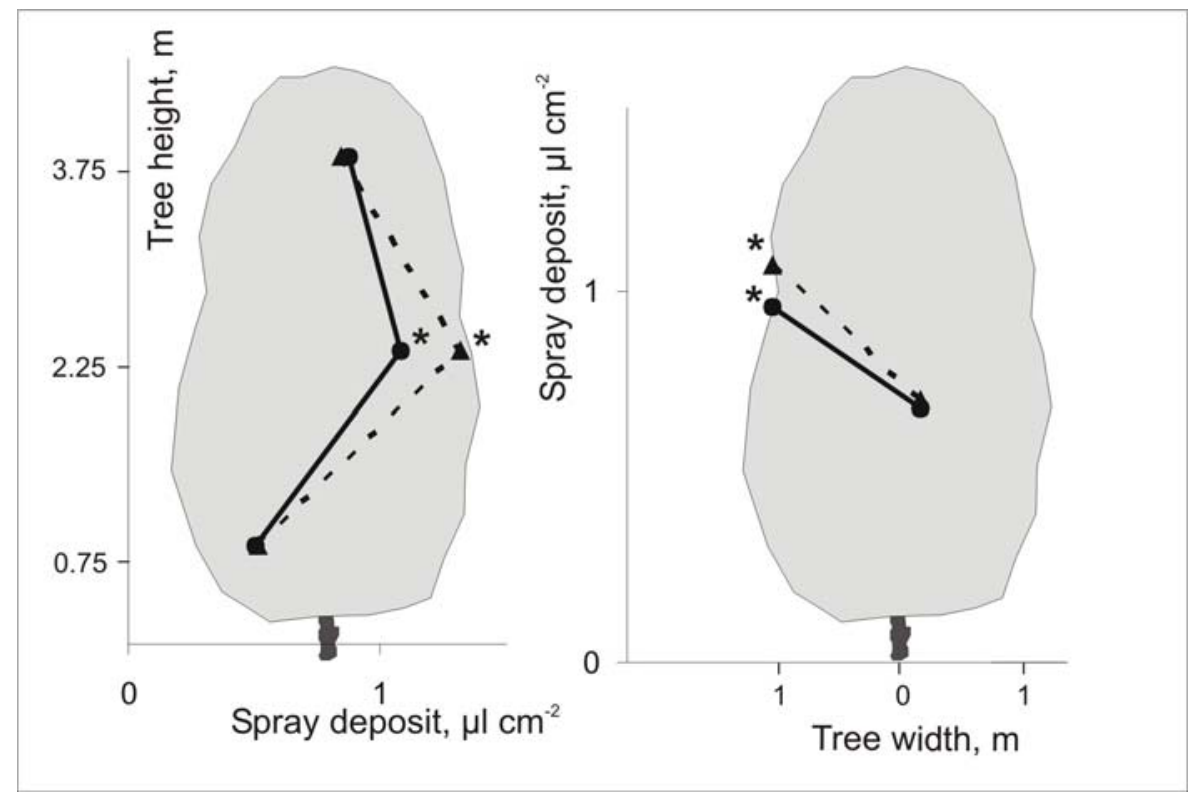

Fig. 5. Spray deposition on the apple tree canopies with the proportional $C_{50}(\longrightarrow)$ and the conventional (....-) application; spray deposit values are shown as the amount of liquid per unit leaf area; (*) significant values (Duncan's Multiple Range Test, $P=0.05$ ) 


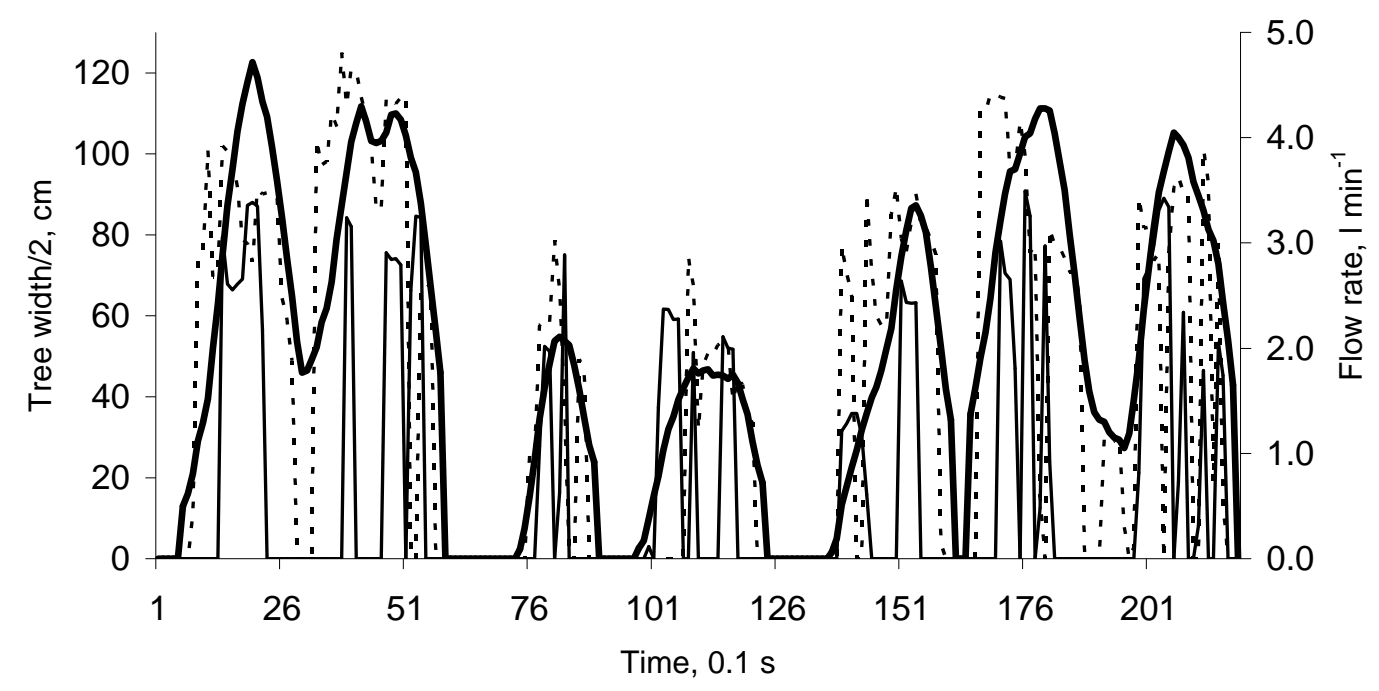

Fig. 6. Measurement of the tree width, with ultrasonic sensors, at the high (-) and low (---) olive canopy levels and measurement of the corresponding liquid flow rate delivered by the sprayer prototype (-); forward speed $0.8 \mathrm{~m} \mathrm{~s}^{-1}$ 


\section{List of figure captions}

Fig. 1. Calculation of the tree canopy width (c) from the distance to the outside of the canopy (d), measured by the ultrasonic sensors; e, distance from the sensor to the sprayer axis; $b$, canopy height; a, tree row spacing

Fig. 2. Hydraulic circuit of the sprayer prototype; $F$, filter; $P$, pump; $R$, pressure regulator; $V$, valve; FM, flow meter; PT, pressure transducer; EV, proportional electrovalve; $A$, anti drip device

10

Fig. 3. Sampling strategy for one replication in the olive orchard trials

Fig. 4. Spray deposition on the (a) olive, (b) pear and (c) apple tree canopies measured after the proportional (—) and conventional (.....) application; spray deposit values are shown as the amount of liquid per unit leaf area

Fig. 5. Spray deposition on the apple tree canopies with the proportional $C_{50}(\longrightarrow)$ and the conventional (.....) application; spray deposit values are shown as the amount of liquid per unit leaf area; (*) significant values (Duncan's Multiple Range Test, $P=0.05$ )

Fig. 6. Measurement of the tree width, with ultrasonic sensors, at the high ( - ) and low (---) olive canopy levels and measurement of the corresponding liquid flow rate delivered by the sprayer prototype (-); forward speed $0.8 \mathrm{~m} \mathrm{~s}^{-1}$ 